strengthening the ties already formed through organisations such as the European Forum for Psychiatric Trainees. In today's climate of a vast increase in mobility of the global medical workforce we would do well to pay heed to the needs of our prospective employers.

DAY, E., GRIMMER, C. \& LLOYD, A. (2002) Psychiatry training in Europe: a brief history of the European Federation of Psychiatric Trainees. Psychiatric Bulletin, 26, 152-154.

Aparna Prasanna Specialist Registrar in Old Age Psychiatry, Memorial Hospital, Shooter's Hill, London SE18 3RZ, email: aparnaprasanna@doctors.org.uk

\section{What's in an MRCPsych!}

There is such passionate debate going on about the award of MRCPsych without examination. Those who have struggled to achieve Membership through examination feel that the value of this has been somewhat lowered or tarnished. I was awarded Membership without examination and would like to share what this means to me and what advantages it has afforded.

Has it helped me to get a job, a promotion, or a higher salary? The answer is no. It is not even recognised in India as a qualification. MRCPsych has not conferred any advantage except receiving the British Journal of Psychiatry and the Psychiatric Bulletin. I definitely did not accept an International Fellowship because of a promise of MRCPsych and I do not mention it on my curriculum vitae.

To me it means the same as my other membership of international and nationa societies, all of which were awarded without examinations! There is no psychiatric society in the UK of which one can become a member except the College. If one could become a member of a professional body only through their own examination, it would be good neither for the professional nor for the professional body.

MRCPsych is an expensive membership to retain. For the annual fee one could get life membership or life fellowship of at least two or three Indian scientific societies. It is not surprising that some who are awarded an honorary MRCPsych are unable to retain it after some years. As far as I am aware, no International Fellow with Membership without examinations has secured a job in the Gulf or other countries where the Membership is acceptable. I am aware of quite a few with the honorary MRCPsych who have taken up assignments in different parts of the world or international organisations. It would be futile to speculate whether the honorary MRCPsych helped them to gain these positions.
I hope those opposing the award of MRCPsych without examination will view the process from the correct perspective and not feel that MRCPsych is some exalted object which they are being robbed of. I am happy to be a member of the College and enjoy participating in its activities, and will probably retain Membership as long as I can afford it!

Declaration of interest S.K.C. was awarded MRCPsych without examination under the International Fellowship Scheme in 2004

Santosh K. Chaturvedi Professor of Psychiatry, National Institute of Mental Health and

curosciences, Bangalore, India, email: chatur@nimhans.kar.nic.in

\section{Referral of older adults with dementia, acetylcholinesterase inhibitors and the NICE guidelines}

Drs O'Loughlin \& Darley suggest that the rate of referral of older adults with dementia has increased since the launch of acetylcholinesterase inhibitors and the publication of the National Institute for Clinical Excellence (NICE) guidelines for their use (Psychiatric Bulletin, April 2006, 30, 131-134). Although the authors acknowledged the limitations of their findings, there are serious ethical and practical objections to the conclusions drawn

We are not clear whether the 42000 people aged 65 years and over in the catchment area was for 1996 or 2003. Fluctuation in the size of this population could easily affect the referral rate. More over, the authors do not define criteria used for the diagnosis of dementia in either period

Mini-Mental State Examination (MMSE) scores are dependent on the person administering the test, age and particularly education (Crum et al, 1993). The difference in the mean MMSE scores between the two groups reported by O'Loughlin \& Darley is just 2.8. Other cognitive scales such as the Alzheimer's Disease Assessment Scale - Cognitive subscale (ADAS-COG) or Mini-Cog have greater reliability and validity (Borson et al, 2005).

Hence, unless the above have been satisfactorily answered, we cannot support the tentative conclusion that more patients are being referred earlier in the course of illness to old age psychiatric services following the launch of anticholinesterase inhibitors and publication of the NICE guidelines.
BORSON, S., SCANLAN, J. M., WATANABE, J., et al (2005) Simplifying detection of cognitive impairment: comparison of the Mini-Cog and Mini-Mental State Examination in a multiethnic sample. Journal of the American Geriatric Society, 53, 871-874.

CRUM, R. M., ANTHONY, J. C., BASSETT, S. S., et al (1993) Population-based norms for the mini-menta state examination by age and educational level. JAMA, 269, 2386-2391.

* Mukesh Kripalani Tees and North East Yorkshire NHS Trust, St Luke's Hospital, Middlesbrough TS4 3AF, e-mail: drmukesh@doctors.org.uk, Ishwari Poongan Senior House Officer in Old Age Psychiatry, Tees, Esk and Wear Valley NHS Trust

\section{Statistical assessment of MMSE scores}

It is disappointing that the interesting study by O'Loughlin \& Darley (Psychiatric Bulletin, April 2006, 30, 131-134) was let down by the use of inappropriate statistics. Since scores on the Mini-Mental State Examination (MMSE) constitute data that are ordinal in nature, it is not appropriate for the mean to be presented as a measure of central tendency. For the same reason, it is not appropriate for standard deviation to be offered as a measure of dispersion. Use of the median and interquartile range (IQR) would have been more appropriate. Similarly, use of the $t$-test as a test for difference between the two groups was ill considered because MMSE scores in both study populations are negatively skewed. The authors should have used a non-parametric test for difference such as the Mann-Whitney U-test.

For the record, the median MMSE score was 20 (IQR 16-24) in the 1996 sample and 22 (IQR 19-25) in the 2003 sample. Running the authors' data through a Mann-Whitney test on StatCrunch (available at http://www.statcrunch.com) still finds a significant difference between the two groups ( $P=0.0037)$.

Alastair Willis Medical Officer (Mental Health) Wāhi Oranga, Nelson Hospital, Private Bag 18, Whakatū 7001, New Zealand e-mail: Alastair.Willis@nmhs.govt.nz

Authors' reply The nature of pragmatic research is to examine clinical practice in the manner it happens - that is both its weakness (for example, not using research-standardised diagnostic interviews or detailed cognitive testing) and its strength. The MMSE has been in use in both clinical and research settings since 1975 as a tool for cognitive assessment and Drs Kripalani and Poongan are correct in stating the unreliability of a single cutoff point for any diagnosis. In our study we examined MMSE scores only of those patients with a diagnosis of dementia, and 
other than commenting on the rise in total number of referrals made no comment on the underlying referral rate.

We agree with Dr Willis that the MMSE, assuming that it measures an actual underlying 'cognitive ability' where the intervals between adjacent scale values are indeterminate, is an ordinal rather than an interval or ratio scale and corresponding tests should be used. We are pleased to note that our data still show significant move towards earlier referral in dementia.
*Christopher O'Loughlin Specialist Registrar in Old Age Psychiatry, Older People's Mental Health Service, Box 311, OPMHS Office, Fulbourn Hospital, Cambridge CB1 5EF, email: c.oloughlin@ btinternet.com, Jon Darley Consultant in Old Age Psychiatry, West Suffolk Hospital, Bury St Edmunds

\section{the college}

\section{What will one CCT mean for us?}

On 3 July 2006 we emailed members and fellows to inform them of Council's decision that the College should apply to change from six certificates of completion of training (CCTs) to one CCT. We have been asked some questions about this change and here are the answers to the most frequently asked questions.

\section{Why the changes and why now?}

Several sub-specialties in psychiatry (e.g addictions, liaison, rehabilitation and neuropsychiatry) have been trying to obtain specialty status, but the Department of Health has not approved these because of difficulties in getting these changes through the UK Parliament. We have also been told that no new applications for CCTs would receive support from the Postgraduate Medical Education and Training Board (PMETB)

If a single CCT is approved by Parliament then the initiative will be with the College to ask PMETB to approve new sub-specialty curricula as they evolve or change. This gives the responsibility back to the College to determine what is good for patients and the profession.

The time is right now so that trainees entering the unified training grade will know what CCT they will receive on completion of training. However, it is likely to take a long time to go through the UK and European parliaments and the final decision will not be made by August 2007.

\section{How many specialist}

curricula have been approved by PMETB (the new regulatory body for medical education)?

The PMETB has approved the six specialist curricula that currently have a CCT. There are currently some non-CCT specialties recognised for article 14

\section{How long will it take for a trainee to obtain one CCT? Will it be longer or shorter than it currently takes?}

It will take about 6 years, as now. It might take some trainees longer and some trainees less time to obtain one CCT.

\section{When will trainees} complete core training and specialist training?

'Core' training will normally take 3 years and will end once the MRCPsych has been passed. 'Optional training in accredited specialties' generally will start at ST4. However, the whole period in the unified training grade will be called specialist training.

\section{When will trainees be} selected for specialist training, for example in forensic psychiatry or psychotherapy?

Allocation into specialty training will take place after the MRCPsych has been passed, as now. Every trainee will be expected to pursue specialist training following one of the approved curricula.

\section{If there is only one CCT,} what will my entry on the specialist register say?

Your entry should reflect the specialist curriculum you have completed, i.e. if you have followed the learning disability programme your entry will read psychiatry (learning disability psychiatry), and if you have followed the child and adolescent training programme your entry will say psychiatry (child and adolescent psychiatry). In the future the specialist register is expected to include much more information about an individual specialist's qualifications and competencies.
When will the change take place?

At this stage, the move to one CCT is a recommendation and may not be approved by the UK and European parliaments. There will be extensive consultations by the Department of Health. It may be 6 years before the changes are implemented. These changes should hopefully be in place by the time trainees entering the unified training grade in August 2007 will be finishing their training, i.e. around 2013.

\section{Will psychiatric specialties} be dumbed down?

Absolutely not! The Royal College of Psychiatrists is committed to developing the best specialist expertise, as our patients and carers expect. Faculties and their educational committees will submit their curricula and ensure that specialist competencies are clearly identified.

Professor Sheila Hollins President Professor Dinesh Bhugra Dean Royal College of Psychiatrists

\section{Medical Director Initiative}

The College Strategic Plan 2005-2010 includes a proposal to harness in a more systematic way the considerable influence of medical directors, and through them to work more effectively with healthcare managers. Peter Kennedy, a former medical manager, chief executive and co-director of the prototype for the National Institute of Mental Health for England (NIMHE) regional development centres was elected Vice-President by Council in January 2006 to lead this initiative.

The founding meeting of the Medical Directors' Executive (MDE) took place on 6 April and defined terms of reference. Each Division will have two medical director nominations to the MDE, one as main member and one as deputy. The MDE will advise the President and College on key issues that need to be taken forward at College level. The College will be more influential working in partnership 